\title{
Umbilical-cord-derived Mesenchymal Stem Cell Transplantation Ameliorated Severe Leg Ulcers in a Patient with Rheumatoid Arthritis: A Case Report and Review of the Literature
}

\author{
Jinyun Chen, Dandan Wang, Xia Li, LinyuGeng, Huayong Zhang, Xuebing Feng and Lingyun Sun* \\ Department of Rheumatology and Immunology, the Affiliated Drum Tower Hospital of Nanjing University Medical School, China
}

\begin{abstract}
Most lower extremity ulcers in patients with rheumatoid arthritis (RA) will become chronic non-healing ulcers without treatments. However, established therapies, including glucocorticoid and immunosuppressive agents didn't show a good efficacy. Some studies have shown umbilical-cord-derived mesenchymal stem cells (UC-MSCs) could accelerate the healing of cutaneous wounds in mice. But no clinical trials of UC-MSCs in cutaneous wound healing have been reported in human. Here we found that UC-MSCs transplantation promoted the healing of ulcers in a RA patient who underwent no improvement with established therapies. This case showed the prospective of UC-MSCs' application in treating recurrent ulcers in RA patients.
\end{abstract}

Keywords: Mesenchymal stem cell; Stem cell; Transplantation; Ulcers; Rheumatoid arthritis

\section{Introduction}

Lower extremity ulcers are recognized complications of rheumatoid arthritis (RA), and most of them will become chronic nonhealing ulcers without treatments. Established therapies, including glucocorticoid and immunosuppressive agents can take a long time to heal the wounds and, additionally, not all patients respond well to these treatments [1]. In recent years, endothelial progenitor cells (EPCs) [2], bone-marrow-derived mononuclear cells (BM-MNCs) [3], fibrocytes [4] and karotinocytes [5] have been shown to be helpful in the healing process of leg ulcers. In a rat diabetic wound healing model, systemic and local treatment with bone-marrow-derived mesenchymal stem cells (BM-MSCs) also demonstrated efficacy [6].

Umbilical-cord-derived mesenchymal stem cells (UC-MSCs) are stem cells derived from the umbilical cord stroma, which can differentiate into a number of cell types including adipocytes, chondrocytes, osteocytes, cardiomyocytes, skeletal myocytes, hepatocytes, insulin-producing cells, as well as neuron-like cells [7]. They have been shown to accelerate the healing of cutaneous wounds in mice $[8,9]$. However, no clinical trials of UC-MSCs in cutaneous wound healing have been reported in RA patients. Here we present the first case of a 42-year-old RA patient with severe large ulcers on the leg who was treated successfully by UC-MSCs transplantation.

\section{Material and Methods}

\section{Case presentation}

A 42-year-old female with 28-year history of RA (fulfilling the ACR classification criteria [10]) presented with recurrent ulcers on her right leg for 6 months. The ulcers distributed along the right thigh with a size of $40 \mathrm{~cm} \times 50 \mathrm{~cm}$, and right gluteal, extensor aspect of right knee and lateral aspect of right ankle with the sizes from $2 \mathrm{~cm} \times 3 \mathrm{~cm}$ to 7 $\mathrm{cm} \times 8 \mathrm{~cm}$ (Figures 1a and $1 \mathrm{~b}$ ). There were yellow purulent secretion, scattered necrotic tissue and hyperalgesia at the ulcers. Chest CT showed lung interstitial disease combined with infection. After therapy with anti-infection, immunosuppression, and regional clearances at local hospital for months, her condition did not improve. She was then transferred to our hospital for further evaluation and therapy. Review of systems revealed 28 years of repeated symmetric swelling and tenderness of small joints, mainly involving two hands. Her past medical history was negative aside from hypertension (HP) and type 2 diabetes mellitus (type $2 \mathrm{DM}$ ).

On examination, the patient was conscious and afebrile. Her lungs were clear to auscultation except for crepitation on the left lower lung. Both hands showed ulnar drift deformity, with limited extension of the wrists. No swelling or tenderness of joint was found, with disease activity score $($ DAS28) $<2.6[11]$.

C-reactive protein (CRP) and erythrocyte sedimentation rate (ESR) were $90 \mathrm{mg} / \mathrm{dl}$ and $43 \mathrm{~mm} / \mathrm{h}$ respectively (normal range: CRP 0-8 $\mathrm{mg} / \mathrm{L}$, ESR 0-20 mm/h). Fasting blood glucose was $4.7 \mathrm{mmol} / \mathrm{l}$ (normal range: 3.9-6.1 mmol/L). Skull CT and MRI showed no significant abnormalities. Secretion culture of the ulcers revealed Staphylococcus aureus and Pseudomonas aeruginosa infection.

During hospitalization, the patient got developing headache, but she refused lumbar puncture. She also denied surgical intervention and was then treated with glucocorticoid, cyclophosphamide (I.V.), broad spectrum antibiotics, debridement and necessary nutritional support. BP and blood glucose were controlled stably. However, two weeks later the ulceration still had not ameliorated. So allogeneic UC-MSCs transplantation was then considered.

The transplantation was administered after the approval of The Ethics Committee of the Affiliated Drum Tower Hospital of Nanjing University Medical School and patient's informed consent. UC-MSCs were obtained from Jiangsu Stem Cell Center, Jiangsu, China, and

*Corresponding author: Lingyun Sun, Department of Rheumatology and Immunology, The Affiliated Drum Tower Hospital of Nanjing University Medical School, Nanjing 210008, China, Tel: 008602583107038; Fax: 008602583107038; E-mail: lingyunsun@nju.edu.cn

Received January 14, 2014; Accepted February 12, 2014; Published February 14,2014

Citation: Chen J, Wang D, Li X, Geng L, Zhang H, et al. (2014) Umbilical-cordderived Mesenchymal Stem Cell Transplantation Ameliorated Severe Leg Ulcers in a Patient with Rheumatoid Arthritis: A Case Report and Review ofthe Literature. J Stem Cell Res Ther 4: 169. doi:10.4172/2157-7633.1000169

Copyright: ( 2014 Chen J, et al. This is an open-access article distributed unde the terms of the Creative Commons Attribution License, which permits unrestricted use, distribution, and reproduction in any medium, provided the original author and source are credited. 
Citation: Chen J, Wang D, Li X, Geng L, Zhang H, et al. (2014) Umbilical-cord-derived Mesenchymal Stem Cell Transplantation Ameliorated Severe Leg Ulcers in a Patient with Rheumatoid Arthritis: A Case Report and Review ofthe Literature. J Stem Cell Res Ther 4: 169. doi:10.4172/21577633.1000169

Page 2 of 3

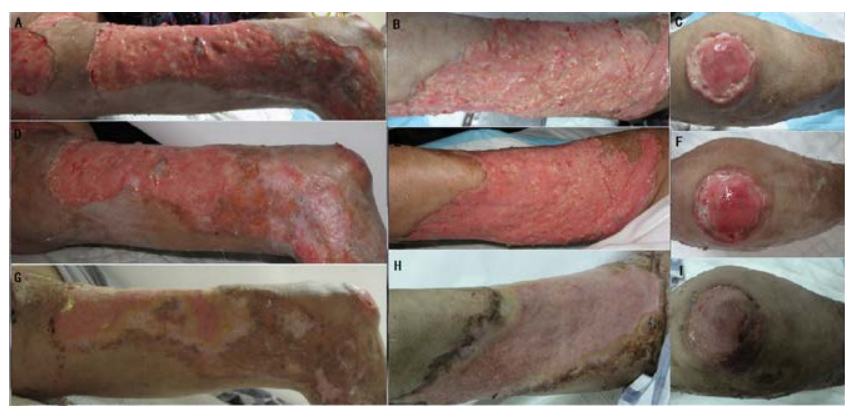

Figure 1: Healing of the ulcers on the right thigh (outer side and inner side) and knee after UC-MSCT. (A-C) before MSCT; (D-F) about one month after the first MSCT; (G-I) about three months after the first MSCT.

prepared for transplantation as previously described [12]. Briefly, umbilical cord (UC) was obtained from local maternity hospitals after normal deliveries and then digested and cultured for 2 generations. After 2 passages cells were harvested. Flow cytometric analysis showed CD29, CD44, and CD105 expression of $>95 \%$, in parallel with CD45, CD34, CD14, and HLA-DR expression of $<2 \%$. We used good manufacturing practice (GMP) conditions and clinical-grade reagents for preparation of the cells.

A total of $5 \times 10^{7}$ cells $\left(1 \times 10^{6}\right.$ cells per kg of the patient's weight $)$ were administered intravenously within 20 minutes after intravenous infusion of methylprednisolone at $40 \mathrm{mg} /$ day $\times$ one time before the transplantation to avoid allergy. The procedure for UC-MSC transplantation was the same as our previous usage in SLE patients [13]. The patient was carefully monitored during and $24 \mathrm{~h}$ after the treatment (including heart rate, blood pressure and consciousness) and no obvious side effects were observed.

\section{Results}

\section{Ulcers healing}

About one month after the first transplantation, we could see growth of granulation tissue at the ulcers (Figure 1D-1F). Two additional transplantations with the same amount of MSCs 1.5 months and 3 months after the first transplantation were given. And we could see significant improvements of the ulcers (Figure 1). After about 3 months the ulcers had significantly healed, with methylprednisolone $10 \mathrm{mg} /$ day for maintenance (Figures 1G-1I).

\section{Infection}

However, the patient's headache continued developing, accompanied by fever and vomiting. Cerebrospinal fluid (CSF) examination demonstrated 43 leukocytes/ $\mu$ l (normal range: 0-8/ $\mu \mathrm{L})(58 \%$ neutrophils, $38 \%$ lymphocytes and $4 \%$ monocytes) under microscope with clear appearance, which indicated central nervous system (CNS) infection. CSF biochemistry showed $1.37 \mathrm{mmol} / \mathrm{l}$ glucose (normal range: $2.5-4.5 \mathrm{mmol} / \mathrm{L}$ ), $125.7 \mathrm{mmol} / \mathrm{l}$ chloride (normal range: $120-132 \mathrm{mmol} / \mathrm{L}$ ), $908.6 \mathrm{mg} / \mathrm{l}$ protein (normal range: $150-450 \mathrm{mg} / \mathrm{L}$ ). Pathologic diagnosis indicated $12 / \mu \mathrm{l}$ Cryptococcus with prolification and mild CNS infection. CSF culture indicated Cryptococcus neoformans proliferation, which was also present in blood culture. Sputum culture and fungi culture found yeast-like fungi, clindamycin-resistant Staphylococcus aureus, methicillin resistant staphylococcus aureus $(+)$ and Candida albicans. After 2 weeks of antibiotic and anti-fungi therapy, with the use of vancomycin, ciprofloxacin, 5-fluorouracil, fluconazole intravenously, her headache alleviated and the protein level of CSF decreased. However, her headache aggravated and both Cryptococcus and protein level of CSF increased after another 11 days. And we began to treat her with additional intrathecal injections of amphotericin $B$ from then on. In spite of the effectiveness of amphotericin B, her liver and renal function gradually worsened because of the side effect. After injections for 3 months, we had to stop amphotericin B. And a few days later, she succumbed to the CNS infection finally.

\section{Discussion}

A postal survey administered to 1,130 RA patients in West Yorkshire, England, taken in 2008, revealed a point prevalence of foot ulceration in RA of 3.39\%, and an overall prevalence of $9.73 \%$ [14]. In a 3 year study of 366 RA patients, evaluated at Georgetown Division of Rheumatology, $4.37 \%$ had active leg ulcers [8]. Leg ulcers in RA patients tended to be resistant to local therapy; conventional treatments often aimed at stabilization of the underlying autoimmune disease, e.g. with high doses of glucocorticoids or other potent immunosuppressive agents. In the Georgetown study, only $31.25 \%$ had healed with the treatment of non-biologic disease-modifying anti-rheumatic drugs (DMARDs) alone or combined with anti-TNFa agents after a mean of 22.76 months of follow-up with ameanhealing time of 32.7 months [1]. Some studies have shown the efficacy of autologous bone marrow derived stem cell transplantation in chronic cutaneous wounds, such as end-stage chronic critical limb ischemia or diabetic foot $[15,16]$. The umbilical-cord-blood-derived MSCs (UCB-MSCs) when applied to cutaneous wounds, demonstrated enhancement in wound healing in an immunodeficientBalb/C SCID mouse model [8]. Tark et al applied UCB-MSCs to diabetic wounds in a study utilizing Leprdb mouse model, demonstrating that MSCs from human cord blood accelerated healing when injected locally [9]. However, no clinical trials of umbilical-cord-derived MSCs in cutaneous wound healing were reported despite the encouraging efficacy in animal models.

In our case, the patient had a long duration of RA, with concomitant diabetes and infection. After sufficient anti-infection and debridement, no trend of improvement could be seen. While after transplantation of UC-MSCs, the sizes of ulcers began to decrease in 2 months, which indicated the prospective of UC-MSCs transplantation in recalcitrant ulcer treatment.

Some previous researches demonstrated that stem cells could mobilize and home to ischemic and wounded tissue where they secreted chemokines and growth factors that promoted angiogenesis and extracellular matrix (ECM) remodeling, creating a local environment conducive to wound healing [17-20]. Besides multiple-differentiating capacity in regeneration, UC-MSCs seem to have a profound effect on immune-regulation [21,22]. In patients with autoimmune diseases, proinflammatory environment may be an important reason for nonhealing ulcers. So the inhibition of inflammatory factors by UC-MSCs could play a crucial role in the underlying mechanism.

This patient succumbed to CNS infection which seemed to exist before transplantation. Impaired immunity due to long term use of glucocorticoid and immunosuppressive and exposure to infection because of large ulcers should be responsible for her death. Though her condition improved with the intrathecal injections of amphotericin $\mathrm{B}$, the side effect of liver and renal function worsening forced us to stop it, which led to her final death from the development of CNS infection. Additionally, a systemic review and meta-analysis of clinical trials did not find an association of MSCT with infection, organ system complications or death [23]. Our own experience of MSCT in systemic lupus erythematosus also showed long-term safety [13]. Several studies 
Citation: Chen J, Wang D, Li X, Geng L, Zhang H, et al. (2014) Umbilical-cord-derived Mesenchymal Stem Cell Transplantation Ameliorated Severe Leg Ulcers in a Patient with Rheumatoid Arthritis: A Case Report and Review ofthe Literature. J Stem Cell Res Ther 4: 169. doi:10.4172/21577633.1000169

Page 3 of 3

even found infusion of MSC could reduce the risk of infection and improve survival in human [24] or mice [25]. So we don't think the infection and death of the patient were due to transplantation.

The potential risks of MSC therapy, including (i) immunogenicity of the cells, (ii) biosafety of medium components, (iii) risk of ectopic tissue formation, and (iv) potential in vitro transformation of the cells during expansion, have been taken into account in one review [22]. According to currently available experimental and clinical data, MSC treatment for autoimmune disorders is feasible and safe [13,22,26]. Nevertheless, to demonstrate the exact mechanism, the safety, treatment efficacy as well as the optimal dose and interval, more clinical controlled trials of UC-MSCT with a long-term follow up in human subjects are necessary.

\section{Acknowledgements}

We are indebted to Gerry Wilson for critical revision of the manuscript. This study was supported in part by grants from the National Natural Science Foundation of China (No. 81172847, 81273304).

\section{References}

1. Shanmugam VK, DeMaria DM, Attinger CE (2011) Lower extremity ulcers in rheumatoid arthritis: features and response to immunosuppression. Clin Rheumatol 30: 849-853.

2. Lee MJ, Kim J, Lee KI, Shin JM, Chae JI, et al. (2011) Enhancement of wound healing by secretory factors of endothelial precursor cells derived from human embryonic stem cells. Cytotherapy 13: 165-178.

3. Sivan-Loukianova E, Awad OA, Stepanovic V, Bickenbach J, Schatteman GC (2003) CD34+ blood cells accelerate vascularization and healing of diabetic mouse skin wounds. J Vasc Res 40: 368-377.

4. Kao HK, Chen B, Murphy GF, Li Q, Orgill DP, et al. (2011) Peripheral blood fibrocytes: enhancement of wound healing by cell proliferation, reepithelialization, contraction, and angiogenesis. Ann Surg 254: 1066-1074.

5. Paquet P, Quatresooz P, Braham C, Pierard GE(2005) Tapping into the influence of keratinocyte allografts and biocenosis on healing of chronic leg ulcers: split-ulcer controlled pilot study. Dermatol Surg 31: 431-435.

6. Kwon DS, Gao X, Liu YB, Dulchavsky DS, Danyluk AL, et al. (2008) Treatment with bone marrow-derived stromal cells accelerates wound healing in diabetic rats. Int Wound J 5: 453-463.

7. Can A, Balci $D$ (2011) Isolation, culture, and characterization of human umbilical cord stroma-derived mesenchymal stem cells. Methods Mol Biol 698: 51-62.

8. Luo G, Cheng W, He W, Wang X, Tan J, et al. (2010) Promotion of cutaneous wound healing by local application of mesenchymal stem cells derived from human umbilical cord blood. Wound Repair Regen 18: 506-513.

9. Tark KC, Hong JW, Kim YS, Hahn SB, Lee WJ, et al. (2010) Effects of human cord blood mesenchymal stem cells on cutaneous wound healing in leprdb mice. Ann Plast Surg 65: 565-572.

10. Arnett FC, Edworthy SM, Bloch DA, McShane DJ, Fries JF, et al. (1988) The
American Rheumatism Association 1987 revised criteria for the classification of rheumatoid arthritis. Arthritis Rheum 31: 315-324.

11. van der Heijde DM, van T HM, van Riel PL, van de Putte LB (1993) Development of a disease activity score based on judgment in clinical practice by rheumatologists. J Rheumatol 20: 579-581.

12. Sun L, Wang D, Liang J, Zhang H, Feng X, et al. (2010) Umbilical cord mesenchymal stem cell transplantation in severe and refractory systemic lupus erythematosus. Arthritis Rheum 62: 2467-2475.

13. Wang D, Zhang H, Liang J, Li X, Feng X, et al. (2013) Allogeneic mesenchymal stem cell transplantation in severe and refractory systemic lupus erythematosus: 4 years of experience. Cell Transplant 22: 2267-2277.

14. Firth J, Hale C, Helliwell P, Hill J, Nelson EA (2008) The prevalence of foot ulceration in patients with rheumatoid arthritis. Arthritis Rheum 59: 200-205.

15. Falanga V, Iwamoto S, Chartier M, Yufit T, Butmarc J, et al. (2007) Autologous bone marrow-derived cultured mesenchymal stem cells delivered in a fibrin spray accelerate healing in murine and human cutaneous wounds. Tissue Eng 13: $1299-1312$.

16. Prochazka V, Gumulec J, Chmelova J, Klement P, Klement GL, et al. (2009) Autologous bone marrow stem cell transplantation in patients with end-stage chronical critical limb ischemia and diabetic foot. Vnitr Lek 55: 173-178.

17. Wu Y, Wang J, Scott PG, Tredget EE (2007) Bone marrow-derived stem cells in wound healing: a review. Wound Repair Regen 15: S18-S26.

18. Kataoka K, Medina RJ, Kageyama T, Miyazaki M, Yoshino T, et al. (2003) Participation of adult mouse bone marrow cells in reconstitution of skin. Am J Pathol 163: 1227-1231.

19. Wu Y, Chen L, Scott PG, Tredget EE (2007) Mesenchymal stem cells enhance wound healing through differentiation and angiogenesis. Stem Cells 25: 26482659.

20. Li H, Fu X, Ouyang Y, Cai C, Wang J, et al. (2006) Adult bone-marrow-derived mesenchymal stem cells contribute to wound healing of skin appendages. Cell Tissue Res 326: 725-736.

21. Soleymaninejadian E, Pramanik K, Samadian E (2012) Immunomodulatory properties of mesenchymal stem cells: cytokines and factors. Am J Reprod Immunol 67: 1-8.

22. Bernardo ME, Fibbe WE (2012) Safety and efficacy of mesenchymal stromal cell therapy in autoimmune disorders. Ann N Y Acad Sci 1266: 107-117.

23. Lalu MM, McIntyre L, Pugliese C, Fergusson D, Winston BW, et al. (2012) Safety of cell therapy with mesenchymal stromal cells (SafeCell): a systematic review and meta-analysis of clinical trials. PLoS One 7: e47559.

24. Tan J, Wu W, Xu X, Liao L, Zheng F, et al. (2012) Induction therapy with autologous mesenchymal stem cells in living-related kidney transplants: a randomized controlled trial. JAMA 307: 1169-1177.

25. Hall SR, Tsoyi K, Ith B, Padera RJ, Lederer JA, et al. (2013) Mesenchyma stromal cells improve survival during sepsis in the absence of heme oxygenase-1: the importance of neutrophils. Stem Cells 31: 397-407.

26. Xu J, Wang D, Liu D, Fan Z, Zhang H, et al. (2012) Allogeneic mesenchyma stem cell treatment alleviates experimental and clinical Sjogren syndrome. Blood 120: 3142-3151. 